\title{
Employment of the new advanced structural materials in the military vehicles and heavy equipment
}

\author{
Tomasz ŚLEZZAK
}

Faculty of Mechanical Engineering, Military University of Technology, ul. gen. Witolda

Urbanowicza 2, 00-908 Warsaw, Poland

E-mail: tomasz.slezak@wat.edu.pl

\begin{abstract}
This paper presents a review of the advanced materials used in the structure of a novel armor systems and the bodies or frames of the military equipment and vehicles. One of the most often materials engaged in armors are the ceramics among of which the aluminium oxides are the widest spread. Nevertheless, there are more advanced ceramics alike a silicon carbide or boron carbide used for example to shield the pilots of assault helicopters. The section of the paper concerning the materials for the bodies is focused on the high strength steels and the conditions of appropriate joints realization. The examples of the welding imperfections were showed and its influence on the structure integrity was discussed taking into account also others factors.
\end{abstract}

KEY WORDS: ballistic protection, armor system, ceramics, nanomaterials, high strength steel, welded structures, construction design

\section{Introduction}

A force protection and preservation of the mobility are ones of the most important issues which must fulfill the military equipment within the battlefield or widely, on the combat zone. The combat vehicles, means of conveyance or equipment of supporting units must be designed with taking into account their destination and basic tasks that should be done. In each case they move through the combat zone on roads, tracks or cross-country, when the ability to move in the last one case is always necessary. Nowadays, the requirements of appropriate protection level are defined not only for combat vehicles, weapons carriers or personnel carriers. More often it is an option for logistic vehicles operating in areas when can be endangered by rifle firing or fragments from artillery indirect fire. Regardless of the armor type it is mounted to ensure appropriate protection level of the crew and to shield crucial components of the vehicle i.e. an engine with their equipment, a drive system, a weapon or electronic systems. Secondly, protection of some supply classes must be guaranteed, like for ammunition, explosives or mines.

Additional armor always increases the total weight of the unit and make worse the ability of forces to movement on the battlefield. For this reason, it is necessary to use the novel lightweight materials or materials with improved ballistic protection capabilities on the armor protective systems like ceramics, composites or nanomaterials. They are characterized by higher level of protection simultaneously with decreased specific weight. On the other hand, these materials are very characteristic and cannot be joined by using welding technologies and other are insufficient. Therefore, full-sized elements of structure like crew hatches or ramp doors are manufactured, otherwise shaped protective panels are mounted by using screws, rivets or special mounting systems.

The weight of military vehicles is increasing despite the use of new protective materials. It is caused by the necessity to mount or carry novel weapon systems, power generators or numerous additional specific equipment. For this reason, self-supporting structures of the vehicles or frames are designed and made of high strength steels. The usage of steel is necessary because it is much better weldable than other structural alloys. Utilization of the modern high strength structural steels (HSS) leads mainly to the reduction of the structure weight. Variable grades are widely adopted in civil applications on frames or highly loaded components to increase the capacities of mobile cranes, trucks, trailers and others. Except the above mentioned advantages, HSS steels are less sensitive to welding compared to common used mild steels due to their microstructure stabilized by micro alloyed additions and exploited strengthening mechanism. It cause that thicker elements can be welded without preheating. On the other side the welding technology must be low hydrogen and made weldments of high quality due to the sensitivity of HSS steels on imperfections or discontinuities. These defects can be the origins of fatigue cracking and result in the failure of structure. For this reason numerous different precautions are taken on each stage of production, from design to manufacture.

\section{Ceramics, Laminates and Nanomaterials in Armor Systems}

The exigency to ensure suitable level of mobility and protection cause that many modern protective materials are developed. High-explosive anti-tank (HEAT) warheads and kinetic energy penetrators (armor-piercing AP) are used 
on battlefield to destroy enemy over years. Armors produced by casting or welding of rolling armor steel are very often homogenous and then have decreased ability to protect the crew against penetrating factors. This is not important whether the armor was exposed to action of a high-velocity superplastic jet of liquid metal from HEAT projectile or the high velocity penetrators made of tungsten or special steel alloys which pierce the armor by kinetic energy. Equally, HEAT and AP projectiles are extremely effective against above mentioned classic armors. An increase in thickness is not appropriate solution and causes deterioration of vehicle mobility. For this reason advanced types of ballistic panels were developed. Ceramic components or composite systems are one of the most popular solutions.

Ceramics are one of the most advanced armor materials what is caused by their effectiveness as disruptors. There can be distinguished both opaque and transparent ceramics made of oxides and nonoxides including also the amorphous glasses. However, ceramic is brittle and contain pre-existing manufacturing flaws which give rise to some bulk properties. Ceramic tiles do not exist as separate elements [1,2]. They are normally very difficult to shape and are manufactured in the simple form of square or hexagon. This materials as result of the impact of projectile disrupt by crumble through their brittleness, what is caused by an extremely high hardness. For this reasons it is a necessity to employ proper technical solutions allowing effective utilization of this group of material. Lightweight ceramic armors consist of a ceramic tiles bonded to a backing plate as shown in Fig. 1. The role of the ceramic is to erode and break up an impacting projectile, whereas the backing plate have two aims: firstly, together with the ceramic it increase stiffness of compound to delay the onset of ceramic tensile fracture, and secondly, this plate absorbs some of the impact energy of the projectile through plastic strains.

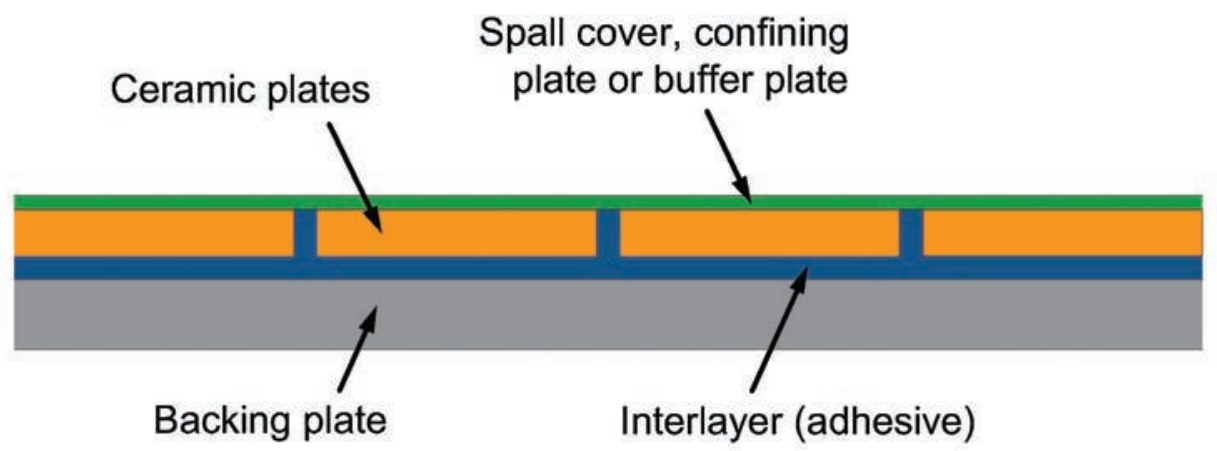

Fig.1. Configuration of a lightweight ceramic armor system

The failure process associated with the penetration of ceramic armors is explained schematically in Fig. 2. Here is presented an example of an armor-piercing projectile impacting an armor ceramic system consisting of ceramic segment and deformable bonded multilayered backing plate.

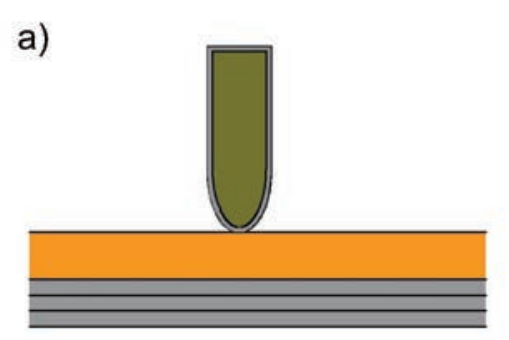

d)

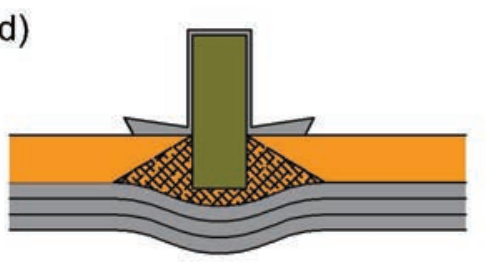

b)

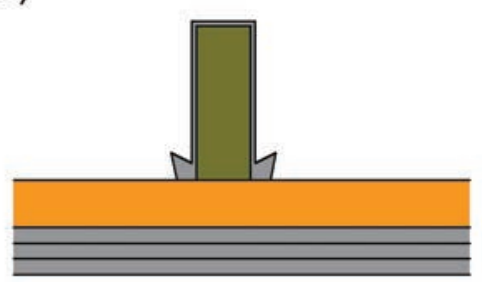

e)

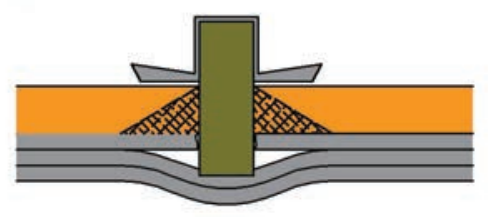

c)

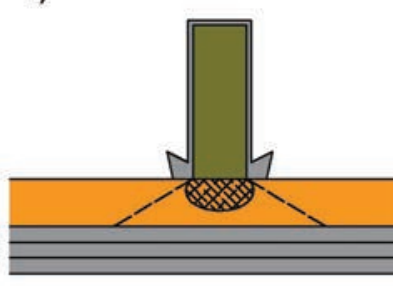

f)

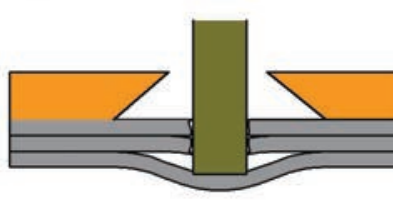

Fig.2. Schematic of typical sequence of physical events during the penetration of an ceramic armor- detailed description in text [3]

First picture (Fig. 2a) shows start position when the hard-cored, jacketed projectile gains contact with the shielded target. Initially, the jacket begins to get stripped out of impact zone and the tip of core is eroded. The core becomes more blunt and loses small volume of its mass (Fig. 2b). Afterwards the cone formation stage takes place 
(Fig. 2c) when around the point of impact the Herzian cracks are initiated and then the conoidal fracture follows. The formation of the conoid increases the area of contact with the backing material. At this phase of impact the ceramic component is locally brought to repentance and the core starts to penetrate the armour. Initially eroded core pierces the comminuted area of rubble and continues the erosion (Fig. 2d). Advancing core causes the pressure which influences the backing plate material causing its deformation in the form of bulge what absorbs energy principally through membrane stretching. Next, the eroded, blunt core exerts through-thickness compression in backing material. Consequently, the backing plate begins to delaminate (Fig. 2e). At the last phase of penetration when the core comes to rest in the rear layers of the light ceramic armor, most of the fractured ceramic from the point of impact gets ejected and removes energy from the impact site (Fig. 2f) [3]. It must be stated, that not all types of cracking absorb energy or the absorption ability is very limited. In the work of Woodward et al.[4] was calculated that fracture of any kind absorbs less than 1\% of the total impact energy. However, the ceramic rubble ejected as front spall removed a large proportion of the total energy. Moreover, the formation of radial cracks from the point of impact takes place, followed by circumferential cracking of the plates. Mentioned second type of cracks are induced by the bending moment from distorted backing plate bonded together with ceramics. This cause the cracks on the tension site.

Nowadays tree basic groups of ceramic materials are used for the armor systems: aluminum oxides, silicon carbides and boron carbides including their numerous modifications. It is most important that the ballistic efficiency against small arms ammunition increase with purity of composition, because it is connected with the material hardness. That's way ceramic armor panels are very often used to provide personal protection against blast or ballistic threat.

First aluminum oxides ceramic armor panels were developed over 40 years ago. AD85 grade, with an alumina content of $85 \%$, was the standard material in use for helicopter applications, as well as body armor plates [3]. Numerous investigations are made in order to achieve the most effective aluminium oxides armor composition. For example some tests were made to assess ballistic efficiency. The most important factor is the ratio of projectile diameter to plate thickness. Comparable tests were made using AD95 and AD995 aluminas by the ratio of 0.8 to 1.0 [5]. As had been expected the AD995 grade had superior ballistic properties. But in some cases the results were variant, eg. if the tile thickness was changed from 10 to $14 \mathrm{~mm}$, the ballistic efficiency decreased for theoretically more advanced AD995 and simultaneously increased for standard AD95. More over nowadays the attempts are made to improve the aluminium oxides by modification using zirconia or nanotubes [6,7].

Second group of ceramic materials applied in the armor systems are silicon carbides, especially the grade known as SiC-N. The Si-C composition has a ballistic efficiency greater than the aluminas, mainly due to its higher hardness, but also due to its consistent performance across the full range of small arms ammunition. Nevertheless, the silicon carbides are difficult in production, because they are manufactured using different additives, sintering aids and also different process controls. For this reason this ceramic materials are very expensive. That's way numerous research attempts are made to limit the costs using other production processes or dry-pressed powders [3].

Boron carbides are the last group of ceramic materials used in lightweight armor systems and considered in this paper. These carbides are one of the hardest ceramic materials known, falling slightly of diamond or cubic boron nitride. Boron carbides have the density of $\sim 2520 \mathrm{~kg} / \mathrm{m}^{3}$ [8], what means that this value is more than three times lower in comparison with armor steel $\left(\sim 7860 \mathrm{~kg} / \mathrm{m}^{3}\right)$. Its properties like hardness (Vickers $3770 \mathrm{~kg} / \mathrm{mm}^{2}$ ), mechanical properties and density cause that boron carbides are excellent for use with confidence in high-end, weight-driven armor applications i.e. bulletproof vests. But this carbide have two main drawbacks, namely the cost of production and formability. Boron carbides are produced in the form of powder directly or by milling the lumps with very low granularity $(0.1-5 \mu \mathrm{m})$. Next, the powder is sintered at very high temperature (2100-2200 $\square$ ) with the aids of alumina, Cr, Co Ni or glass. Nevertheless, this ceramic material have underperformance of ballistic protection due to shear localization occurring under shock loading. Recent achievements in the area of boron carbides production are focused mainly on the cost reduction what was reached by developing the pressureless sintering operation [3]. Different examples of application the ceramic materials in lightweight armours are presented in Fig. 3.

a)

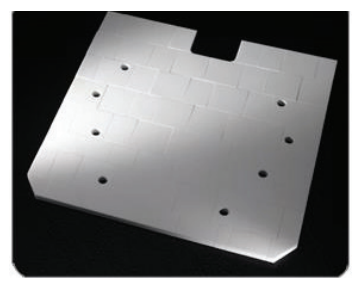

b)

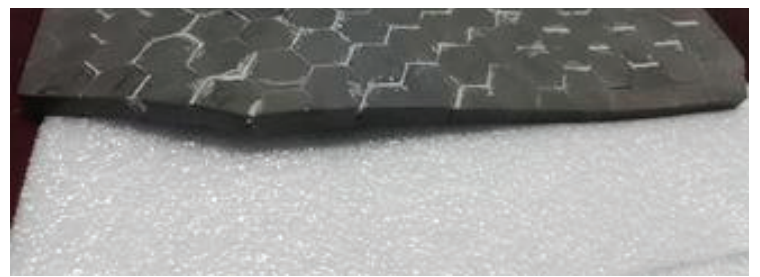

Fig.3. The applications of the ceramic materials: a vehicle protection system made of alumnium oxides (a) [9] and a bulletproof ceramic armor plate made of silicon carbides (b) [10]

Laminates and layered structures are the next category of materials used in armor applications. Already, many years ago it was observed that the layered compositions have more better protection properties than homogenous armors against the high-speed impact of projectile. For this reason numerous new laminated armors were developed. They consist of a few different layers of steel, ceramic, fabrics, polymers or composites. Moreover, the quality of joints between the plies is crucial because an incorrect bonding or a lack of the connection causes significant deterioration of the protection. Layered structure influences the better absorption of impact energy because of the mismatch of physical and mechanical properties. A thin layer 
of bonded adhesive plays often the role of a flexural plate which absorbs the impact and support the joined layers. Due to the specific loads induced by impact, namely compression, shear and three-dimensional bending of materials causing local tension of interlayer, this layer can be fractured by created cohesive delamination, what exemplary was presented in Fig. 4.

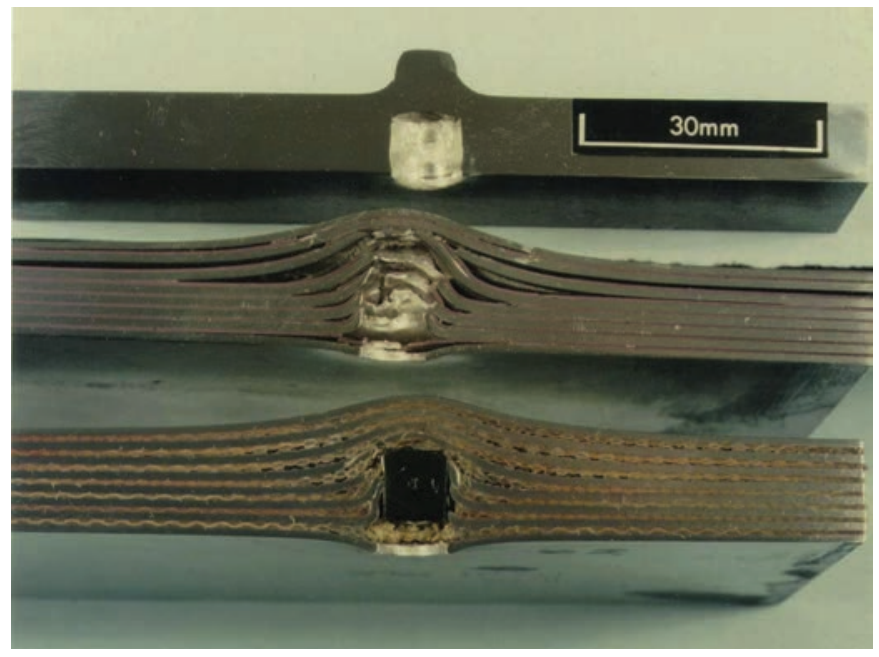

Fig.4. Examples of adhesively bonded aluminium laminates and a monolithic aluminium alloy impacted by a high-velocity fragmentation simulator projectile [11]

Various compositions of materials are designed and tested to obtain stated level of protection. One of them are the adhesive bonded aluminium laminates ABAL, very lightweight which under the same thickness have better properties. Second type of laminates, the steel-composite were developed to avoid the risk of plugging the high-hardness steel plates by rifle ammunition. No more than $9 \mathrm{~mm}$ steel plate is required to stop standard $7.62 \mathrm{~mm}$ rifle ball and then the risk occurs to form a plug. For this reason it was necessary to design new panels with reduced thickness of steel and able to arrest the bullets without plugging. Last considered type of layered compositions is an alumina-aluminium laminate. This case was detailly descripted above but there should be pointed one aspect more, namely the optimum thickness understanding as the relation between thickness of both components. On the basis of the results placed in the [12] can be stated that the thickness of ceramic should be 2-3 times higher than of aluminium.

In this place must be listed other group of layered materials produced by entirely different method of joining. It is a explosively welded materials. This method allows to joint materials which cannot be joint in any other way. Nevertheless, method of explosively welding is limited to ductile materials due to extreme values of strains and its ratio. Laminates of titanium and aluminum alloys are one of the specific solution of light materials with higher ballistic resistance obtaining by explosive welding [13-14]. This laminate is probably a perspective material for aircraft and space application as shielding panels. The case described in [13] showed that the best results were achieved when the projectile impacts on the aluminium side. The purpose of used aluminium alloy AA2519 was to blunt and erode the core. In this configuration the role of titanium alloy is to support more brittle AA2519 and final arrest of the penetrating core. Sometimes in this type of layered lightweight armour materials the interlayer is added to ensure proper bonding of the main panels [Fig. 5].

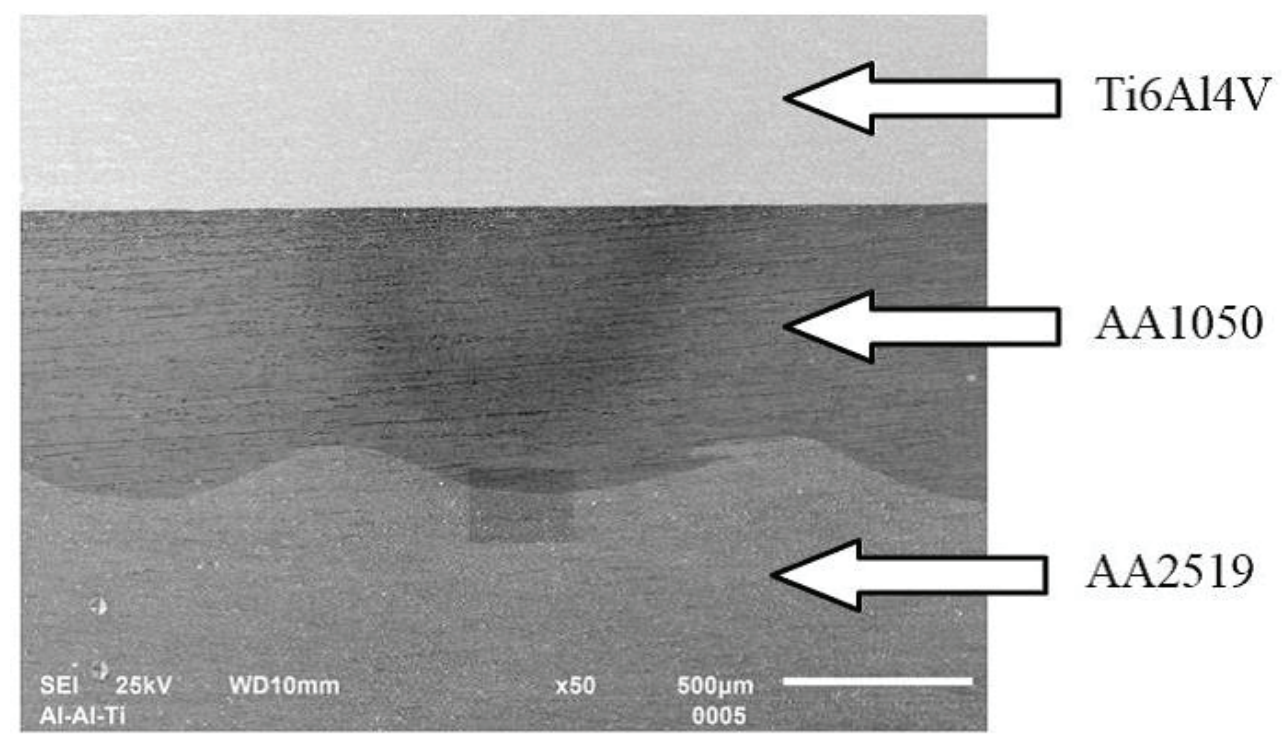

Fig.5. A cross-section of the AA2519-Ti6A14V laminate with the AA1050 interlayer [15] 
The above considered materials nowadays are developed to obtain extremely fine-grained structure up to nanoscale, including composites and armor steels. This group is common known as nanomaterials. The structure consisting of the grains or dispersive elements finer than $1 \mu \mathrm{m}$ is characterized by the very high strength in tension, high hardness and increased capability to dissipate the impact energy by plastic strains. This materials are less brittle in comparison with classic materials which are more brittle simultaneously with the increasing hardness. Additionally, the ceramic materials more often are reinforced using carbon nanotubes due to improve their ability to carry the tensile stresses caused by bending moment or increase the resist on brittle cracking. The examples of practical utilization of nanomaterials in armor systems are showed in Fig. 6.

a)

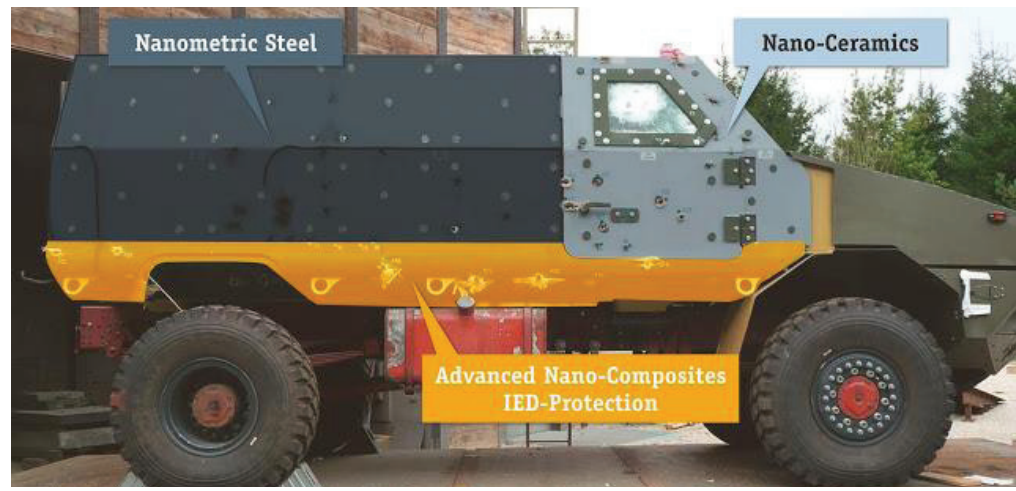

b)

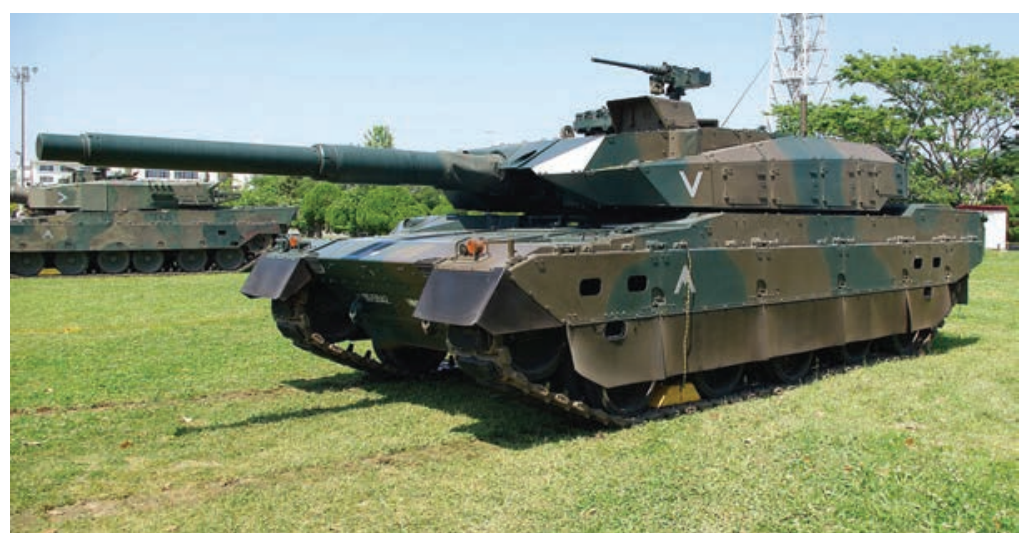

Fig.6. Application of nanomaterials in 4x4 vehicle armor (a) [16] and a nano-crystal steel in the Japanese main battle tank MTB type 10 Hitomaru (b) [17]

Special steels are still used on protective panels or elements of armor i.e. Armox or Ramor steels [18], but the grades of maraging or bainitic nanostructured steels were developed [19-20]. These grades of steel have high hardness and what is more important ultra-high strength above $1.8 \mathrm{GPa}$ with good ductility. According to IBD using advanced steels, composites and ceramic materials, it is possible to achieve the same protection level as with standard materials. An armor weight reduction of more than $40 \%$ is able to reach in the case of $8 \times 8$ vehicle [16].

\section{High Strength Structural Steels HSS}

The structural steels with the tensile strength of more than $600 \mathrm{MPa}$ are commonly used in military vehicles. Higher weight of the military vehicles cause that the structure must be fabricated of steels with high strength and acceptable weldability. In some structures the yield stress of those steels reach the value of $1100 \mathrm{MPa}$ or even above [21]. Besides the vehicles these grades of steels are utilized in special military structures i.e. the military assault and supporting bridges, extremely loaded elements and mechanisms or the trailers for heavy vehicles transportation [22-23]. It is caused by the key benefit of weight reduction of the structure simultaneously with retaining the ability to carry heavy operational loads while driving or firing. HSS steels are used in design of the frames or self-supporting structures of the vehicles first of all than must be weldable and carry alternating loads causing the fatigue. These features are contrary to the high strength due to the fact that while the strength increases together with the hardness the ductility and weldability decrease. For this reason a production process exploiting welding technologies must be performed very carefully. Higher strength of structural steels is obtained in two ways. Firstly, the percentage of alloy additives is increased, however the carbon equivalent rises causing serious deterioration of the weldability. Secondly, advanced techniques of rolling were developed to produce the high strength structure of tempered martensite, bainite or both together with different content. This type of steel is sensitive to thermal cycles taking place during the welding. For the above reasons the appropriate material choose and one of the most important manufacturing process is welding. Serious welding imperfections can occur. Some examples of incomplete penetration and inacceptable porosity in the weldments are presented in Fig. 7. 
a)

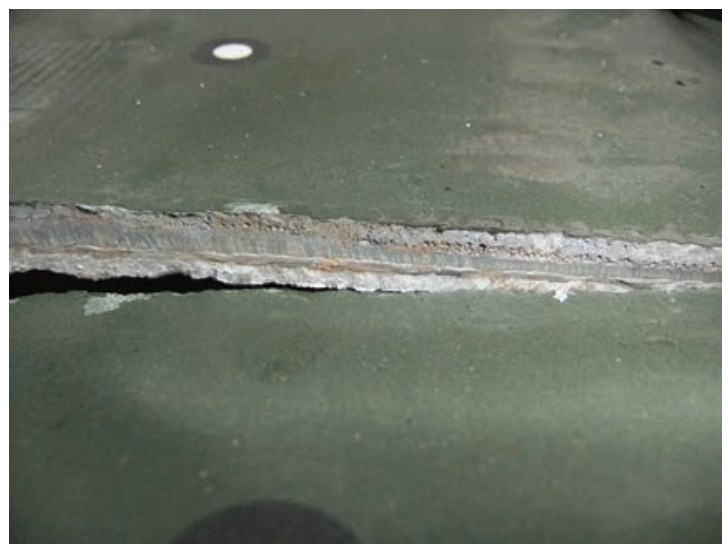

b)

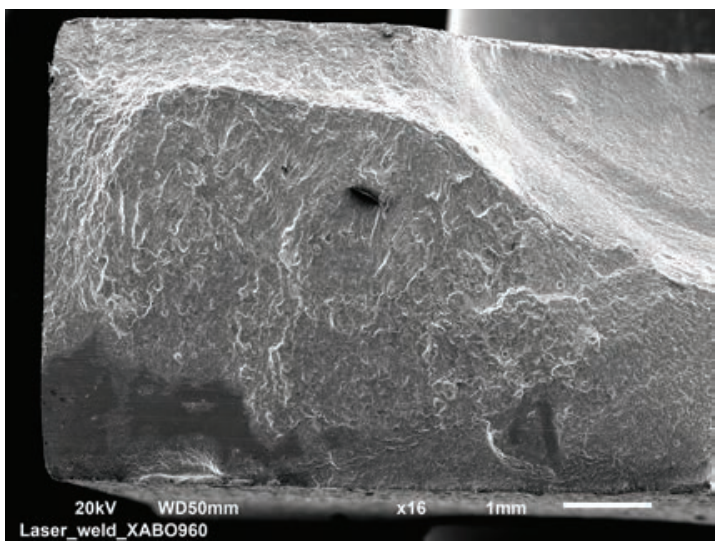

Fig.7. Incomplete penetration and porosity in the weldment high strength armor steel revealed in (a) and incomplete penetration in XABO 960 welded by laser beam (b)

Furthermore, even the welds are realized properly and any imperfections are not detected during the inspection the junctions can failure by cracking. The operational loadings cause the fatigue failures and an occasional exceed of permissible stresses can induce the overload failure. In Fig. 8 are shown the exemplary cracks of the welds at the weld face and in the fusion line.

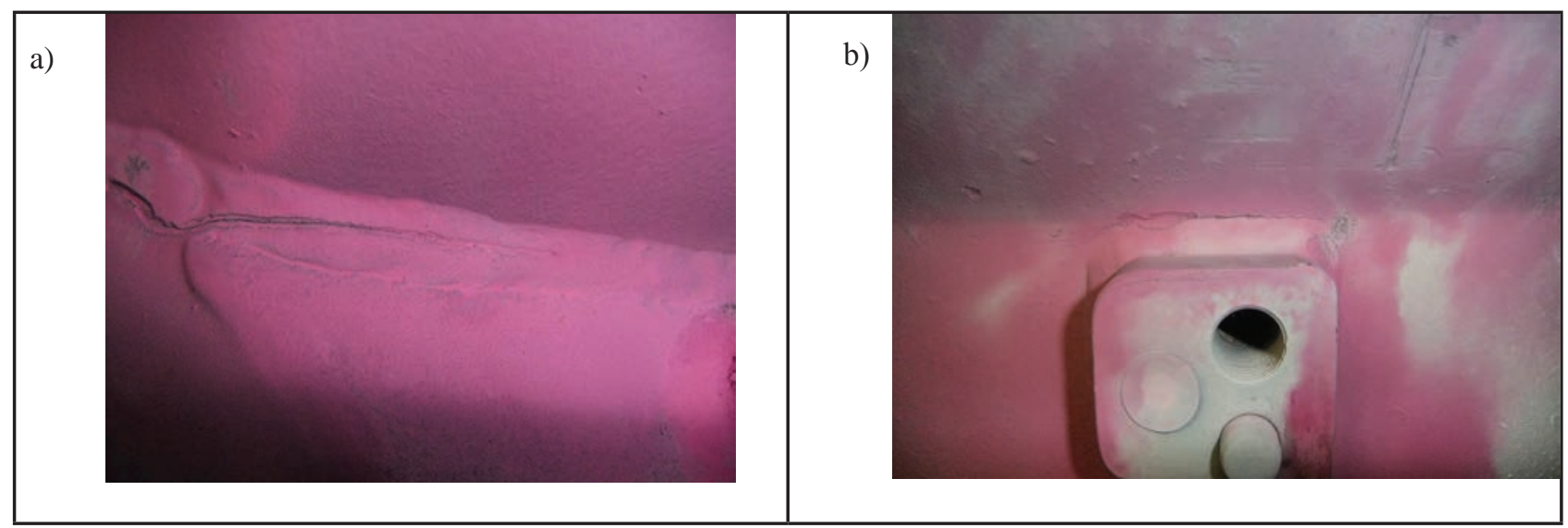

Fig.8.The cracks observed in the weldments made of high strength armor steel at the face weldment

(a) and in the fusion line (b)

The above cracks are caused by a stress concentration in the place of change in shape or an invisible origin. The cracks may initiate from the site of a material discontinuity or hard particles rolled in the surface. In order to decrease the likelihood of damage first of all the construction nodes are properly shaped (Fig. 9)

a)

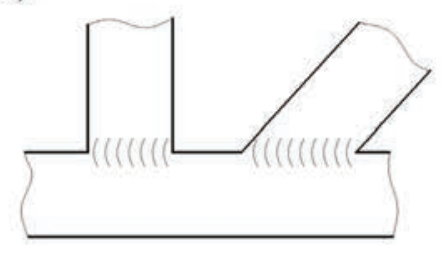

b)

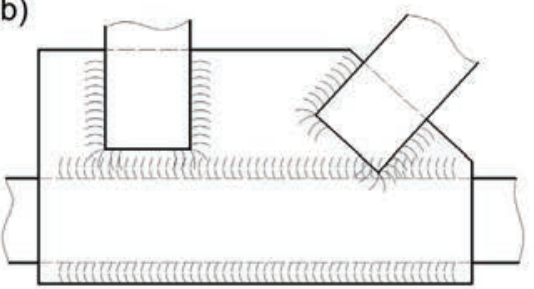

c)

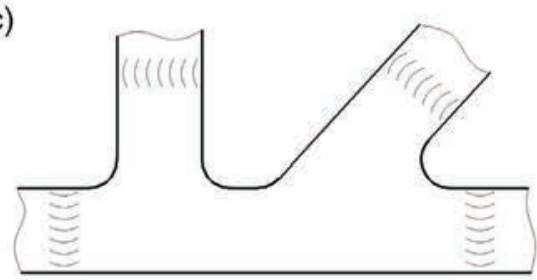

Fig.9.Exemplary different solutions for welded node from the worst, extremely notched (a), through intermediate solution using gusset plate (b) to the best shaped node (c)

Appropriate shape design is the first way to increase an ability to carry the load without damage caused by fatigue. Nevertheless, there are many other methods of modification the welded nodes made of high strength steels. The technique of the fusion line peening is one of the most popular. Using it welding technique is unchanged and an additional process is 
relatively inexpensive and little time-consuming. On the other hand, some special designed stress relief holes or undercuts are realized in the sites of stress concentration.

\section{Conclusions}

A military industry has always been the most advanced among others branches. Combat equipment and armored vehicles are produced using the latest technologies, many of which are developed intendedly to achieve clear defined requirements. The safety of combat vehicles crews is the main aim to be endeavor. Advanced, very effective anti-tank ammunition and rockets cause the need to develop more resistant armors. Classic ballistic shields would have to be thicker and therefore with a heavier weight. For this reason new ballistic materials are developed to ensure adequate level of protection the crew and sensitive components of armament systems. First of all the high-tech armors have to be characterized better ratio of weight to ballistic protection level. Therefore the aluminium oxides, silicon carbides and boron carbides were introduced into the production of armor systems wherein the necessity of usage a very expensive technologies influence the higher costs. An option is to utilize laminate structures or composites, but they can be employ rather in light solutions i.e. bullet-proof jackets or armor systems of light vehicles and personnel carriers. It is slight probability that this objects would be exposed on fire of heavy armament.

New armor materials assist to reduce the military equipment weight which increase still due to fulfill the protection requirements. On the other hand the massive vehicles and another military equipment have to be supported by engineering forces equipped with assault and supporting bridges. This bridges are extremely loaded. Both mentioned examples indicate that the use of high strength steels is inevitable. Moreover, these steels make it possible to face the requirements successful and develop the construction. Nevertheless, this grade of steels is difficult to weld and many conditions should be completed to perform high quality joints. Welding imperfections can weak the junction certainly and finally the whole structure. Therefore all aspects of heavy loaded structures made of high strength steels are extremely important.

\section{References}

1. Cegła M Ceramic materials for armor applications. Problemy Techniki Uzbrojenia 2014; 131: 19-25.

2. Matchen B. Applications of Ceramics in Armor Products. Key Engineering Materials 1996; 122-124: 333-344.

3. Crouch I G. Franks G V, Tallon C, Thomas S, Naebe M. Glasses and ceramics [in:] The Science of Armour Materials, Woodhead Publishing in Materials, Elselvier Ltd, 2017, pp. 331-393.

4. Woodward R I, O”Donnell R G, Baxter B J, Nicol B, Pattie S D. Energy absorption in the failure of ceramic composite armours. Materials Forum 1989; 13:174-181.

5. Madhu V. et al. An experimental study of penetration resistance of ceramic armour subjected to projectile impact. International Journal of Impact Engineering 2005; 32 (1-4): 337-350.

6. Zhang X F, Li Y C. On the comparison of the ballistic performance of $10 \%$ zirconia toughened alumina and $95 \%$ alumina ceramic targets. Materials and Design 2010; 31 (4): 1945-1952.

7. Bolduc M. et al. Towards better personal ballistic protection. in: Paper Presented at the Personal Armour Systems Symposium, Cambridge, UK, September 2014.

8. Crouch I G. Threat-defeating mechanisms in body armour systems. In: Paper Presented at the Next Generation Bosy Armour Conference, London, UK, September 2009.

9. http://ww.ctarmor.com/markets/aerospace_defense/vehicle_armor.php

10. http://www.cathodicprotection-anodes.com/sale-10053942-silicon-carbide-sic-bulletproof-ceramic-body-armorplate-high-bending-strength.html

11. Crouch I G. Laminated materials and layered structures [in:] The Science of Armour Materials, Woodhead Publishing in Materials, Elselvier Ltd, 2017, pp. 168-201.

12. Hetherington $\mathrm{J} \mathrm{G}$. The optimisation of two component composite armours. International Journal of Impact Engineering 1992; 12 (3): 409-414.

13. Szachogluchowicz I, Sniezek L, Mierzynski J, Koperski W. Experimental study on ballistic AA 2519 / Ti6Al4V laminate according to STANAG 4569 Level 1. Proceedings of $11^{\text {th }}$ International Conference Intelligent Technologies in Logistics and Mechatronics Systems 28-29 April 2016, Panevėžys, Lithuania, pp. 155-163.

14. Lazurenko D V, Bataev I A, Mali V I et. al. Explosively welded multilayer Ti-Al composites: Structure and transformation during heat treatment. Materials and Design 2016; 102: 122-130.

15. Szachogluchowicz I., Sniezek L., Hutsaylyuk V. Low cycle fatigue properties of AA2519-Ti6Al4V laminate bonded by explosion welding. Engineering Failure Analysis 2016; 69:77-87.

16. http://www.miltechmag.com/2013_01_01_archive.html

17. https://en.wikipedia.org/wiki/Type_10

18. https://www.ssab.com.

19. Wiśniewski A, Garbarz B, Burian W, Marcisz J. Composite space armours with the bainitic-austenitic and maraging steel layers. Problemy Techniki Uzbrojenia 2013; 128: 33-41. 
20. Garbarz B., Marcisz J., Adamczyk M., Wiśniewski A. Ultrahigh-strength nanostructured steels for armors. Problems of Mechatronics. Armament, Aviation, Safety Engineering 2011; 2 (1): 25-36.

21. Gresnigt A M, Steenhuis C M. High strength steels. Steel Construction 1997; 1: 31-41.

22. Raczyński Z. Badania parametrów wytrzymałościowych przęsła mostu MS-40. Szybkobieżne Pojazdy Gąsienicowe 2015; 36: 99-113 [in polish].

23. Morada P. Examples and applications of high strength steel. by webpage: www.oakleysteel.co.uk/examples-applicationshigh-strength-steel. 